\title{
Maternal omega-3 fatty acid intake during neurodevelopment does not affect pup behavior related to depression, novelty, or learning
}

\author{
Corey Jackson ${ }^{1}$, Douglas W. Barrett² , Jason Shumake², Elisa Gonzales ${ }^{1}$, F. Gonzalez-Lima² \\ and Michelle A. Lane ${ }^{1 *}$ (1)
}

\begin{abstract}
Objective: Previously, we showed that consumption of a diet supplemented with omega-3 polyunsaturated fatty acids (n-3FAs) for two rounds of gestation and lactation increased the ability of rat dams to cope with stress when compared to dams that ingested a diet lacking n-3FAs. The objective of this study was to determine if the diets of these dams affected the behavior of their pups later in life. To isolate the neurodevelopmental effects of n-3FAs, pups from the second gestation were weaned to a diet adequate in n-3FAs. Pup testing began at 8 weeks of age and consisted of the forced swim, open field, and hole board tests to examine depression-related behavior, reaction to novelty, and learning and memory, respectively.

Results: Given the considerable difference in the n-3FA content of the maternal diet, we expected a large effect size, however with the exception of rearing duration, maternal diet did not affect behavior in any of the tests conducted. These results suggest that maternal n-3FA supplementation during neurodevelopment likely does not affect offspring behavior when a diet adequate in n-3FA is provided post-weaning. Rather, we hypothesize that brain n-3FAs at the time of testing confer altered behavior and corroborate the need for additional research.
\end{abstract}

Keywords: n-3 fatty acids, Depression, Novelty reactivity learning, Memory, Neurodevelopment

\section{Introduction}

Fetuses and neonates depend on docosahexaenoic acid (DHA), an omega-3 polyunsaturated fatty acid (n-3FA), via the placenta or milk to meet neurodevelopmental demands [1]. Higher maternal seafood intake and serum n-3FA concentrations during human pregnancy and lactation are often associated with increased infant neurocognitive development $[2,3]$ and cognitive, attentional, and emotional benefits lasting into childhood [4-9]; however, much work, including meta-analyses, shows no effects [10-12].

\footnotetext{
*Correspondence: ML48@txstate.edu

${ }^{1}$ Nutrition and Foods Program, School of Family and Consumer Sciences, Texas State University, 601 University Dr., San Marcos, TX 78666, USA

Full list of author information is available at the end of the article
}

Rodent studies support the relationship between n-3FA consumption and beneficial behavioral outcomes [13-21], but few isolate the function of n-3FAs prior to weaning, during neurodevelopment. Our objective was to fill this gap. We used dams consuming disparate diets either deficient in or supplemented with n-3FAs through two rounds of gestation and lactation. This deficient diet reduced brain $\mathrm{n}$-3FAs in dams [22, 23] and neonates [17]. In our previous study, supplemented dams exhibited an increased ability to cope with stress when compared to deficient dams [24]. In the current study, pups from the dams used in [24] were weaned to a diet containing adequate n-3FA levels for 5 weeks prior to behavioral testing. Because n-3FA levels were altered solely in the maternal diet but not in the pup diet after weaning, we could isolate behaviors potentially altered by maternal n-3FA 
intake during gestation and lactation, a crucial neurodevelopmental period.

\section{Main text \\ Methods \\ Animals and diets}

N-3FA deficient or supplemented diets were administered to Long Evans dams through two cycles of pregnancy and lactation (see Additional file 1). Maternal diets were manufactured by Research Diets, Inc. (New Brunswick, NJ), based on AIN-93G. Dams in the "without n-3FAs" group consumed diets with 7\% sunflower oil. The "with n-3FAs" group ingested diets with 7\% menhaden oil, consisting of $14.2 \%$ eicosapentaenoic acid (EPA) and $10.3 \%$ DHA.

Two days after parturition, litters were culled to eight pups, four/sex, when possible. Pups were housed with their dams until weaning at 21 days. Male pups from the second gestation of dams in [24] were used. Pups were from separate litters. Pups were weaned to the standard facility diet containing $6.7 \%$ fat $(\mathrm{w} / \mathrm{w})$, adequate $\alpha$-linolenic acid $(0.2 \%$ [25]), and negligible EPA and DHA. The fatty acid composition is in [24]. To simplify terminology, pup group names reflect the dams' n-3FA intake.

Pups were habituated to handling prior to behavioral testing. Testing began 5 weeks after weaning, and continued for 7 days. Pups were sacrificed by rapid decapitation following the conclusion of the behavioral work. Protocols were approved by the Institutional Animal Care and Use Committees of the University of Texas at Austin and Texas State University.

\section{Behavioral tests}

The forced swim test (FST) was conducted as in [24]. Rats were observed for $5 \mathrm{~min}$ on day 2. Immobility was assigned to stationary postures, moving only to stay afloat, for more than $3 \mathrm{~s}$.

The open field test (OFT) was performed in two 10-min sessions over two consecutive days [24]. The first day represented a novel; the second day a familiar environment. An activity monitoring system (Med Associates Inc., St. Albans, VT) recorded frequency, duration, speed, location, and the path of movement. Behaviors measured included exploration, average velocity, average rearing duration, time in the center $38 \%$ of the field, and stereotypic time.

The hole board test (HBT) measured nose pokes into a board with a $4 \times 4$ array of holes $2 \mathrm{~cm}$ in diameter, inserted into the OFT apparatus. During each trial, the same four out of 16 holes were baited with a piece of cookie. Pups were exposed to the cookies before testing. Trials began with the first entry and ended after the last bait was consumed or 5 min elapsed. Infrared beams below the floor recorded nose pokes (entries) into each hole. Latency to complete each trial, novel entries, repeat entries, and total entries were recorded by the automated system. Rats experienced five trials/day for three consecutive days.

\section{Statistical analyses}

Data for all subjects is included in figures. Data are expressed in tabular form in Additional files 2, 3, 4, and 5 as mean \pm SEM, mean differences and $95 \%$ confidence intervals of the mean differences (CI) for $\mathrm{n}=10$ deficient and $n=7$ supplemented pups unless indicated. Mean differences due to maternal diet were calculated by subtracting the value for the n-3FA deficient group from the supplemented group; thus, positive values indicate supplemented $>$ deficient. Mean differences over time were calculated by subtracting the first day of testing from the last. Levene's tests for equality of variance determined if Welch's or Student's t-tests were appropriate for analysis of behavior in the FST and on isolated days in the OFT and HBT (Additional files 2, 4). Fisher's exact test assessed the proportion of pups with zero vs. non-zero immobility in the FST. Linear Mixed-Effects Modeling determined the effect of maternal diet on behavior over time in the OFT and HBT (Additional files 3, 5). This modeling was repeated dropping one subject at a time to determine if that individual drove the outcome. Statistical analyses were performed using SPSS v. 24 (Chicago, IL). Differences were considered significant at $P<0.05$. The expected power analysis was done using $G^{*}$ Power 3.1 [26].

\section{Results}

Increased FST immobility characterizes depressionrelated behavior $[27,28]$. There was no difference in the amount of time spent immobile due to maternal diet (Fig. 1), mean difference $=33.0 \mathrm{~s}, 95 \%$ CI $(-10.9,77.0)$, $P=0.12$. Maternal diet did not affect whether a pup displayed immobility $(P=0.62)$. Five pups per group exhibited immobility. Two supplemented and five deficient pups showed no immobility (Fig. 1).

Novelty reactivity predicts learned helplessness [29], predisposing to depression [30-32]. Group differences in activity changes between novel and familiar environments were assessed by comparing change in time spent exploring (the sum of ambulatory and rearing time), rearing duration average, and average velocity in the novel vs. familiar open field environments (Fig. 2; Additional file 2), which are reflected by the interaction between diet and time when predicting these metrics (Additional file 3). There was no effect of maternal diet on any parameter (Additional file 2). When modeled 


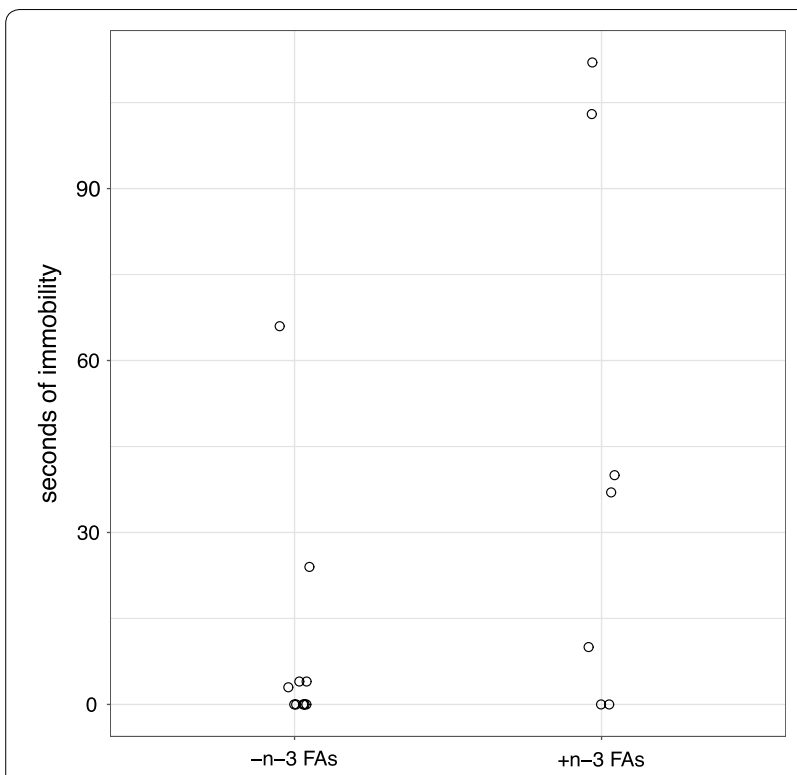

Fig. 1 Effect of maternal $n-3$ FA consumption during neurodevelopment on offspring immobility in the forced swim test. Pups were placed in a cylinder of water, to simulate an inescapable stressor, for 15 min on day 1 and for 5 min on day 2. Day 2 video recordings were scored for immobility. Data shown are seconds of immobility on day 2 for pups with $(+n-3 F A s ; n=7)$ and without $n-3$ FAs during neurodevelopment $(-n-3 F A s, n=10)$

as a whole using linear mixed effects regression taking both maternal diet and day into account, diet did not alter time spent exploring, rearing duration, or average velocity (Fig. 2a-c; Additional file 3). Familiarity increased time spent exploring and rearing duration. A diet by novelty interaction existed for rearing duration. The rearing duration of supplemented pups remained relatively constant, while deficient pups increased their rearing duration between days (Additional files 2, 3). Due to the lack of response to maternal n-3FA intake on other parameters predictive of novelty response we believe this interaction is spurious and that, overall, n-3FA consumption during neurodevelopment has no effect on novelty reactivity.

Increased time spent in the center of the OFT environment reflects decreased fear, elevated risk-taking, or a combination thereof. Stereotypic movement signifies hyperactivity [33]. There were no effects of maternal diet or novelty on center or stereotypic time and no interactions (Fig. 2d, e; Additional files 2, 3).

The HBT assessed learning and memory. The reference memory ratio equaled the number of entries to baited holes divided by the number of total entries (to both baited and unbaited holes). Maternal diet had no effect on reference memory ratios when each day of the HBT was considered separately (Additional file 4). Pups improved their performance across days but maternal diet had no effect on pup performance (Fig. 3a; Additional file 5). There was no interaction between maternal diet and day.

The working memory ratio equaled the number of initial entries to holes divided by the total number of entries plus re-entries to holes. Maternal diet did not affect working memory ratio. Elimination of one subject resulted in an increase in working memory ratio over time (Fig. 3b, Additional file 5). With this pup included the working memory ratio did not change over time [F $(1,15)=1.90, \mathrm{P}$-value $=0.17$, mean difference $=0.12,95 \%$ CI of mean difference $(0.01,0.24)]$. There was no maternal diet by day interaction for working memory.

\section{Discussion}

When subjects themselves ingest increased amounts n-3FAs studies often reveal a positive correlation between n-3FA intake and beneficial behavior. While many designs aim to examine the role of n-3FAs in neurodevelopment, few achieve this because the pups consume the same diet as their dams after weaning through testing. In the current design, dams consumed disparate levels of n-3FAs during gestation and lactation, but their pups ingested adequate n-3FAs from weaning onward, allowing isolation of behaviors perpetually altered by maternal n-3FA intake during neurodevelopment. We found no effect of n-3FA intake on behaviors related to depression, novelty reactivity, and learning and memory.

Others have shown an inverse relationship between depression-related behavior and n-3FA intake in adult rats [13, 34-42]. Those isolating neurodevelopment [21, 43] found that n-3FAs deficiency increased FST immobility in animals replete with n-3FAs post-weaning. Of note, diet did not affect depression-related behavior in the dams of our pups [24]. While we cannot be certain why these discrepancies exist, our use of Long-Evans (versus Sprague-Dawley) rats may contribute as strain affects FST behavior [44].

Studies indicate that as n-3FA intake increases, novelty reactivity decreases whether n-3FAs are consumed post-weaning [45] or from conception [17]. Post-weaning $\mathrm{n}$-3FA supplementation also improves learning and memory in rats exposed to adequate n-3FA levels during neurodevelopment $[34,46]$. Additionally, n-3FA deficiency during and after neurodevelopment decreases learning and brain DHA $[18,20]$. In contrast to our study, in each of the above-mentioned studies n-3FA intake varied at the time of testing; thus, we hypothesize that the effects of n-3FAs on behavior are due to n-3FA levels in the brain during testing.

In conclusion, our work suggests that maternal n-3FA intake during neurodevelopment may not dramatically 


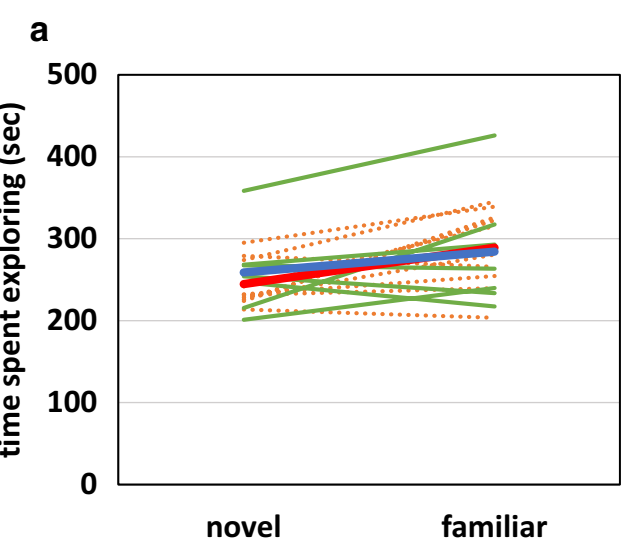

C

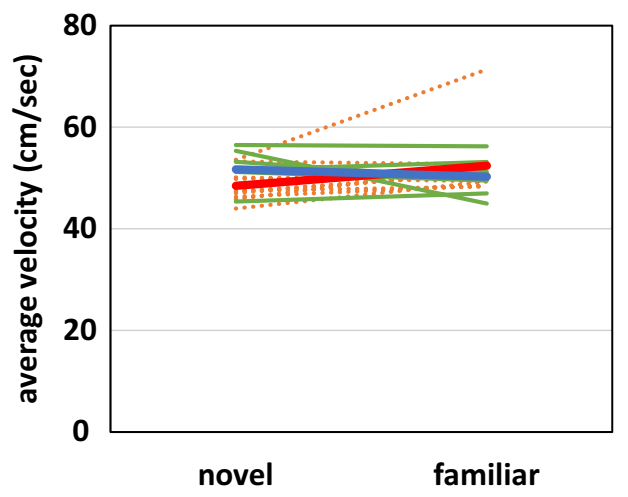

b

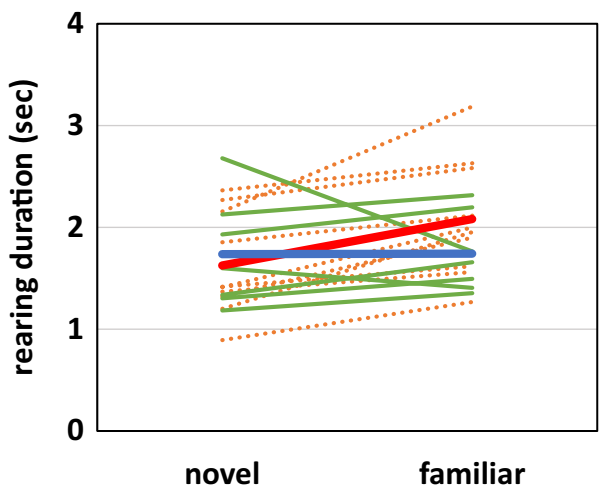

d

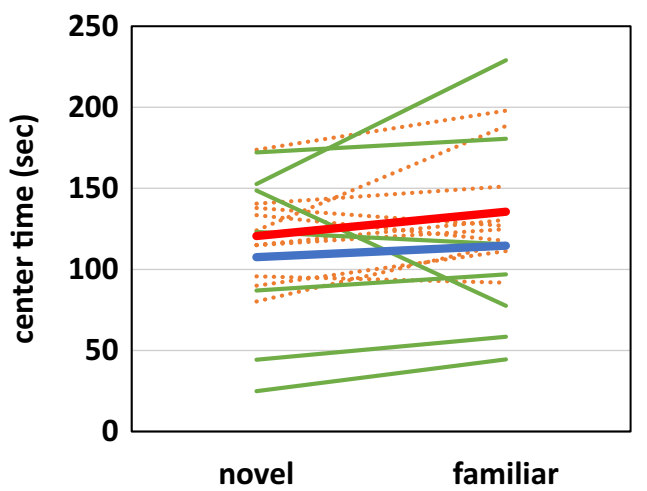

e

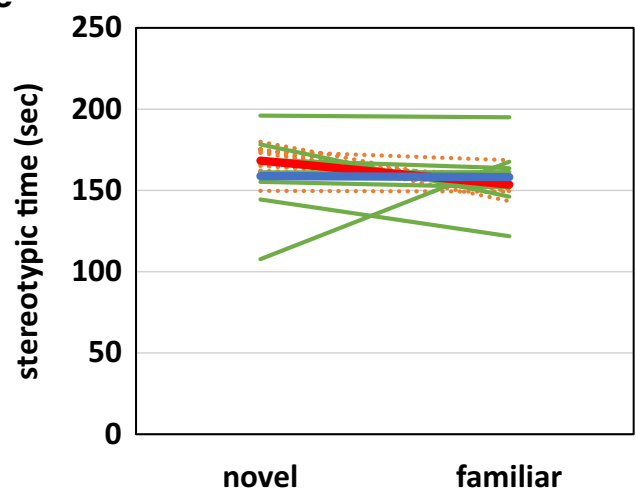

Fig. 2 Impact of maternal n-3 FA consumption during neurodevelopment on offspring behavior in the open field. Pups were placed in the open field chamber for $10 \mathrm{~min}$ on day 1 (novel environment). Twenty-four hours later, pups were returned to the same chamber for another 10-min period (familiar environment). Individual trajectories in the novel and familiar open fields are shown for supplemented $(n=7)$ and deficient $(n=10)$ pups. In each panel, green, solid lines indicate supplemented pups and orange, dashed lines specify deficient pups. The means for supplemented pups are indicated by a thick, blue line. A thick, red line denotes the means for deficient pups. Panels show time spent exploring (a), average rearing duration (b), average velocity (c) center time (d) and stereotypic time (e) 

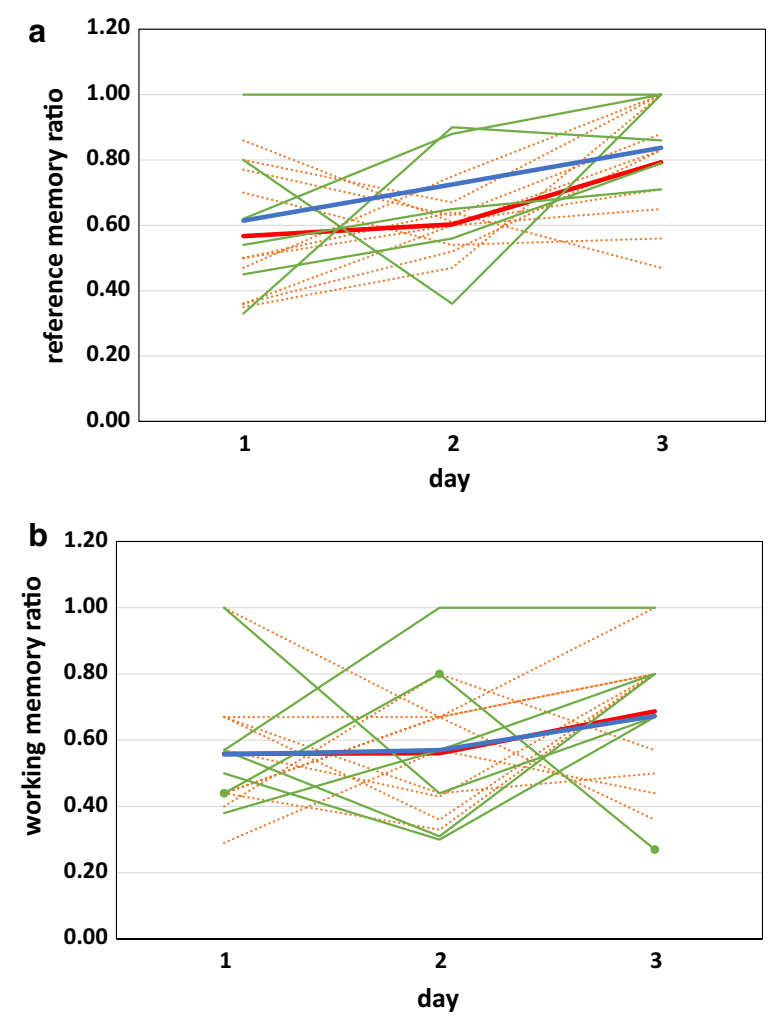

Fig. 3 Consequences of maternal n-3 FA consumption on offspring reference or working memory in the hole board test. Pups were placed in the open field chamber modified to contain a board with a $4 \times 4$ grid and a consistent pattern of baited holes. Rats were subjected to five trials each day for three consecutive days. Individual trajectories are shown for $n-3 F A$ supplemented $(n=7)$ and deficient $(n=10)$ pups. In each panel, green, solid lines indicate supplemented pups and orange, dashed lines specify deficient pups. Solid, circular markers indicate the supplemented pup that was an outlier and not included in the working memory ratio data shown in Additional files 4 and 5 . The mean memory ratios for supplemented pups is indicated by a thick, blue line. A thick, red line denotes the mean memory ratios for deficient pups. a Displays reference memory ratios, $\mathbf{b}$ working memory ratios. One less supplemented pup is included on day 2 for each ratio because data was lost due to an equipment malfunction

alter behavior later in life provided offspring n-3FA intake is adequate postweaning. At behavioral testing, all pups had consumed a diet with adequate n-3FA levels for 5 weeks, theoretically eliminating the effects of disparate maternal diets, resulting in similar brain n-3FA content as in [21, 43]. Additional work is required to test this theory.

\section{Limitations}

Sample size

Studies comparing diets either deficient in or supplemented with n-3FAs to those containing adequate levels have seen very large effect sizes with sample sizes of
6,10 , and 16 per group [14, 16, 18]. Based on these and considering the extreme disparity in n-3FA levels in the maternal diets, we chose $n=10$ /group for both generations. Indeed, we observed very large (Cohen's $d=1.2$ ) or large (Cohen's $d=0.8-0.95)$ effect sizes of diet on dam behavior [24]. Unfortunately, three pups did not complete the study due to factors unrelated to diet. Our final sample size had an expected power of $62 \%$ to detect very large (Cohen's $\mathrm{d}=1.2$ ) mean differences. Button et al. [47] showed that the median power of published neuroscience studies is $21 \%$. Of note, studies with such low power can only obtain $P<0.05$ significant differences if they randomly draw samples that show a much larger mean difference than the expected true effect. The fact that the vast majority of these publications (instead of the expected 21\%) report significant differences reflects publication bias because underpowered studies with positive findings are published while underpowered studies with negative findings are often not. Thus, we conclude that our work was moderately well powered if the effect sizes of similar published studies are accurate estimates of the true effects; else, these previous studies are likely underpowered themselves and are therefore reporting exaggerated effects. Either way, it is important that our current negative findings are taken into account by future research, which should not assume very large effect sizes of n-3FA on behavior when calculating needed sample sizes. In summary, maternal n-3FA intake during neurodevelopment may not markedly effect behavior later in life, but we acknowledge this data does not prove the null and there could be effects of maternal n-3FA intake on offspring behavior that may be detected with a larger sample size.

\section{Lack of brain n-3FA analysis}

The brains were used for other assays so their n-3FA content was not assessed.

\section{Additional files}

Additional file 1. Experimental timeline.

Additional file 2. Table of activity parameters in the novel versus familiar open field.

Additional file 3. Table showing results of linear mixed effects regression analysis of open field activity parameters.

Additional file 4. Table of memory ratios by day in the hole board test.

Additional file 5. Table displaying results of linear mixed effects regression analysis of reference and working memory. 


\section{Abbreviations}

n-3FAs: omega-3 polyunsaturated fatty acids; DHA: docosahexaenoic acid; EPA: eicosapentaenoic acid; FST: forced swim test; OFT: open field test; HBT: hole board test.

\section{Authors' contributions}

ML, JS, DWB, and FGL designed the experiments; EG and DWB performed experiments; CJ analyzed and compiled data, ML and JS performed the statistical analyses, ML, JS, DWB, and FGL wrote the manuscript. All authors read and approved the final manuscript.

\section{Author details}

${ }^{1}$ Nutrition and Foods Program, School of Family and Consumer Sciences, Texas State University, 601 University Dr., San Marcos, TX 78666, USA. ${ }^{2}$ Department of Psychology, The University of Texas at Austin, 108 E. Dean Keeton Stop A8000, Austin, TX 78712, USA.

\section{Acknowledgements}

We are grateful to the many graduate and undergraduate students that participated in this research.

\section{Competing interests}

The authors declare that they have no competing interests.

\section{Availability of data and materials}

Data is available from the corresponding author upon request.

\section{Consent for publication}

Not applicable.

\section{Ethics and approval to participate}

Animal protocols were approved by the Institutional Animal Care and Use Committees (IACUCS) of the University of Texas at Austin and Texas State University and complied with the Guide for the Care of Use of Laboratory Animals.

\section{Funding}

This study was supported by the Texas State University Research Enhancement Program. The funding body played no role in the design of the study, the collection, analysis, and interpretation of data, nor in writing the manuscript.

\section{Publisher's Note}

Springer Nature remains neutral with regard to jurisdictional claims in published maps and institutional affiliations.

Received: 29 Auqust 2018 Accepted: 9 November 2018

\section{Published online: 15 November 2018}

\section{References}

1. Rogers LK, Valentine CJ, Keim SA. DHA supplementation: current implications in pregnancy and childhood. Pharmacol Res. 2013;70:13-9.

2. Hibbeln JR, Davis JM, Steer C, Emmett P, Rogers I, Williams C, Golding J. Maternal seafood consumption in pregnancy and neurodevelopmental outcomes in childhood (ALSPAC study): an observational cohort study. Lancet. 2007:369:578-85.

3. Emmett PM, Jones LR, Golding J. Pregnancy diet and associated outcomes in the avon longitudinal study of parents and children. Nutr Rev. 2015;73(Suppl 3):154-74.

4. Helland IB, Smith L, Saarem K, Saugstad OD, Drevon CA. Maternal supplementation with very-long-chain $n-3$ fatty acids during pregnancy and lactation augments children's iq at 4 years of age. Pediatrics. 2003;111:e39-44.

5. Boucher O, Burden MJ, Muckle G, Saint-Amour D, Ayotte P, Dewailly E, Nelson CA, Jacobson SW, Jacobson JL. Neurophysiologic and neurobehavioral evidence of beneficial effects of prenatal omega-3 fatty acid intake on memory function at school age. Am J Clin Nutr. 2011;93:1025-37.
6. Kannass KN, Colombo J, Carlson SE. Maternal DHA levels and toddler freeplay attention. Dev Neuropsychol. 2009;34:159-74.

7. Loomans EM, Van den Bergh BR, Schelling M, Vrijkotte TG, van Eijsden M. Maternal long-chain polyunsaturated fatty acid status during early pregnancy and children's risk of problem behavior at age 5-6 years. J Pediatr. 2014;164:762-8.

8. Steenweg-de Graaff JC, Tiemeier H, Basten MG, Rijlaarsdam J, Demmelmair H, Koletzko B, Hofman A, Jaddoe VW, Verhulst FC, Roza SJ. Maternal LC-PUFA status during pregnancy and child problem behavior: the Generation R Study. Pediatr Res. 2015;77:489-97.

9. Kohlboeck G, Glaser C, Tiesler C, Demmelmair H, Standl M, Romanos M, Koletzko B, Lehmann I, Heinrich J. Effect of fatty acid status in cord blood serum on children's behavioral difficulties at $10 \mathrm{y}$ of age: results from the LISAplus Study. Am J Clin Nutr. 2011;94:1592-9.

10. Makrides M, Gibson RA, McPhee AJ, Yelland L, Quinlivan J, Ryan P. Effect of DHA supplementation during pregnancy on maternal depression and neurodevelopment of young children: a randomized controlled trial. JAMA. 2010;304:1675-83.

11. Gould JF, Smithers LG, Makrides M. The effect of maternal omega-3 (n-3) LCPUFA supplementation during pregnancy on early childhood cognitive and visual development: a systematic review and meta-analysis of randomized controlled trials. Am J Clin Nutr. 2013;97:531-44.

12. Delgado-Noguera MF, Calvache JA, Bonfill Cosp X, Kotanidou EP, GalliTsinopoulou A. Supplementation with long chain polyunsaturated fatty acids (LCPUFA) to breastfeeding mothers for improving child growth and development. Cochrane Database Syst Rev. 2015. https://doi. org/10.1002/14651858.CD007901.pub3.

13. Ferraz AC, Kiss A, Araujo RL, Salles HM, Naliwaiko K, Pamplona J, Matheuss F. The antidepressant role of dietary long-chain polyunsaturated n-3 fatty acids in two phases in the developing brain. Prostaglandins Leukot Essent Fatty Acids. 2008:78:183-8.

14. Chen HF, Su HM. Fish oil supplementation of maternal rats on an n-3 fatty acid-deficient diet prevents depletion of maternal brain regional docosahexaenoic acid levels and has a postpartum anxiolytic effect. J Nutr Biochem. 2012;23:299-305.

15. Naliwaiko K, Araujo RL, da Fonseca RV, Castilho JC, Andreatini R, Bellissimo MI, Oliveira BH, Martins EF, Curi R, Fernandes LC, et al. Effects of fish oil on the central nervous system: a new potential antidepressant? Nutr Neurosci. 2004;7:91-9.

16. Vines A, Delattre AM, Lima MM, Rodrigues LS, Suchecki D, Machado RB, Tufik S, Pereira SI, Zanata SM, Ferraz AC. The role of 5-HT(1)A receptors in fish oil-mediated increased BDNF expression in the rat hippocampus and cortex: a possible antidepressant mechanism. Neuropharmacology. 2012:62:184-91.

17. Levant B, Zarcone TJ, Fowler SC. Developmental effects of dietary n-3 fatty acids on activity and response to novelty. Physiol Behav. 2010;101:176-83.

18. Moriguchi T, Greiner RS, Salem N Jr. Behavioral deficits associated with dietary induction of decreased brain docosahexaenoic acid concentration. J Neurochem. 2000;75:2563-73.

19. Moriguchi T, Salem N Jr. Recovery of brain docosahexaenoate leads to recovery of spatial task performance. J Neurochem. 2003;87:297-309.

20. Fedorova I, Hussein N, Baumann MH, Di Martino C, Salem N Jr. An n-3 fatty acid deficiency impairs rat spatial learning in the Barnes maze. Behav Neurosci. 2009;123:196-205.

21. Weiser MJ, Wynalda K, Salem N Jr, Butt CM. Dietary DHA during development affects depression-like behaviors and biomarkers that emerge after puberty in adolescent rats. J Lipid Res. 2015;56:151-66.

22. Levant B, Ozias MK, Davis PF, Winter M, Russell KL, Carlson SE, Reed GA, McCarson KE. Decreased brain docosahexaenoic acid content produces neurobiological effects associated with depression: interactions with reproductive status in female rats. Psychoneuroendocrinology. 2008;33:1279-92.

23. Levant B, Ozias MK, Carlson SE. Specific brain regions of female rats are differentially depleted of docosahexaenoic acid by reproductive activity and an (n-3) fatty acid-deficient diet. J Nutr. 2007;137:130-4.

24. Gonzales E, Barrett DW, Shumake J, Gonzalez-Lima F, Lane MA. Omega-3 fatty acids improve behavioral coping to stress in multiparous rats. Behav Brain Res. 2015;279:129-38. 
25. Bourre JM, Piciotti M, Dumont O, Pascal G, Durand G. Dietary linoleic acid and polyunsaturated fatty acids in rat brain and other organs. Minimal requirements of linoleic acid. Lipids. 1990;25:465-72.

26. Faul F, Erdfelder E, Lang AG, Buchner A. G*Power 3: a flexible statistical power analysis program for the social, behavioral, and biomedical sciences. Behav Res Methods. 2007;39:175-91.

27. Lucki I. The forced swimming test as a model for core and component behavioral effects of antidepressant drugs. Behav Pharmacol. 1997:8:523-32.

28. Cryan JF, Valentino RJ, Lucki I. Assessing substrates underlying the behavioral effects of antidepressants using the modified rat forced swimming test. Neurosci Biobehav Rev. 2005;29:547-69.

29. Padilla E, Shumake J, Barrett DW, Holmes G, Sheridan EC, Gonzalez-Lima F. Novelty-evoked activity in open field predicts susceptibility to helpless behavior. Physiol Behav. 2010;101:746-54.

30. Pucilowski O, Overstreet DH, Rezvani AH, Janowsky DS. Chronic mild stress-induced anhedonia: greater effect in a genetic rat model of depression. Physiol Behav. 1993;54:1215-20.

31. Vollmayr B, Bachteler D, Vengeliene V, Gass P, Spanagel R, Henn F. Rats with congenital learned helplessness respond less to sucrose but show no deficits in activity or learning. Behav Brain Res. 2004;150:217-21.

32. Shumake J, Barrett D, Gonzalez-Lima F. Behavioral characteristics of rats predisposed to learned helplessness: reduced reward sensitivity, increased novelty seeking, and persistent fear memories. Behav Brain Res. 2005;164:222-30.

33. Colorado RA, Shumake J, Conejo NM, Gonzalez-Pardo H, Gonzalez-Lima F. Effects of maternal separation, early handling, and standard facility rearing on orienting and impulsive behavior of adolescent rats. Behav Processes. 2006;71:51-8.

34. Ferraz AC, Delattre AM, Almendra RG, Sonagli M, Borges C, Araujo P, Andersen ML, Tufik S, Lima MM. Chronic omega-3 fatty acids supplementation promotes beneficial effects on anxiety, cognitive and depressivelike behaviors in rats subjected to a restraint stress protocol. Behav Brain Res. 2011;219:116-22.

35. DeMar JC Jr, Ma K, Bell JM, Igarashi M, Greenstein D, Rapoport SI. One generation of $n-3$ polyunsaturated fatty acid deprivation increases depression and aggression test scores in rats. J Lipid Res. 2006;47:172-80.

36. Huang SY, Yang HT, Chiu CC, Pariante CM, Su KP. Omega-3 fatty acids on the forced-swimming test. J Psychiatr Res. 2008;42:58-63.
37. Carlezon WA Jr, Mague SD, Parow AM, Stoll AL, Cohen BM, Renshaw PF. Antidepressant-like effects of uridine and omega- 3 fatty acids are potentiated by combined treatment in rats. Biol Psychiatry. 2005;57:343-50.

38. Laino CH, Fonseca C, Sterin-Speziale N, Slobodianik N, Reines A. Potentiation of omega-3 fatty acid antidepressant-like effects with low non-antidepressant doses of fluoxetine and mirtazapine. Eur J Pharmacol. 2010:648:117-26.

39. Lakhwani L, Tongia SK, Pal VS, Agrawal RP, Nyati P, Phadnis P. Omega-3 fatty acids have antidepressant activity in forced swimming test in Wistar rats. Acta Pol Pharm. 2007;64:271-6.

40. Venna VR, Deplanque D, Allet C, Belarbi K, Hamdane M, Bordet R. PUFA induce antidepressant-like effects in parallel to structural and molecular changes in the hippocampus. Psychoneuroendocrinology. 2009:34:199-211.

41. Wibrand K, Berge K, Messaoudi M, Duffaud A, Panja D, Bramham CR, Burri L. Enhanced cognitive function and antidepressant-like effects after krill oil supplementation in rats. Lipids Health Dis. 2013;12:6.

42. Park Y, Moon HJ, Kim SH. N-3 polyunsaturated fatty acid consumption produces neurobiological effects associated with prevention of depression in rats after the forced swimming test. J Nutr Biochem. 2012;23:924-8

43. Chen HF, Su HM. Exposure to a maternal n-3 fatty acid-deficient diet during brain development provokes excessive hypothalamic-pituitaryadrenal axis responses to stress and behavioral indices of depression and anxiety in male rat offspring later in life. J Nutr Biochem. 2013;24:70-80.

44. Bogdanova OV, Kanekar S, D'Anci KE, Renshaw PF. Factors influencing behavior in the forced swim test. Physiol Behav. 2013:118:227-39.

45. Mathieu G, Denis S, Lavialle M, Vancassel S. Synergistic effects of stress and omega-3 fatty acid deprivation on emotional response and brain lipid composition in adult rats. Prostaglandins Leukot Essent Fatty Acids. 2008:78:391-401.

46. Perez MA, Terreros G, Dagnino-Subiabre A. Long-term omega-3 fatty acid supplementation induces anti-stress effects and improves learning in rats. Behav Brain Funct. 2013;9:25.

47. Button KS, loannidis JP, Mokrysz C, Nosek BA, Flint J, Robinson ES, Munafo MR. Power failure: why small sample size undermines the reliability of neuroscience. Nat Rev Neurosci. 2013;14:365-76.
Ready to submit your research? Choose BMC and benefit from:

- fast, convenient online submission

- thorough peer review by experienced researchers in your field

- rapid publication on acceptance

- support for research data, including large and complex data types

- gold Open Access which fosters wider collaboration and increased citations

- maximum visibility for your research: over $100 \mathrm{M}$ website views per year

At $\mathrm{BMC}$, research is always in progress.

Learn more biomedcentral.com/submissions 